\title{
Scheme of Polymer-Ion-clay Interaction and Ion-Ion Interaction In Polymer Nanocomposite Electrolytes Films
}

\author{
M. Sadiq ${ }^{*}$, Anil Arya ${ }^{2}$, Ashish kumar Yadav ${ }^{4}$ Manoj K Singh ${ }^{3}$, Yasir Bhat ${ }^{3}$ \\ and A. L. Sharma ${ }^{2}$
}

\author{
${ }^{1}$ Asst.Pof. Department of Physics, A R S D College, Dhaula Kuan (Delhi University)-11021, India \\ ${ }^{2}$ Centre for Physical Sciences, Central University of Punjab, Bathinda-151001, India \\ ${ }^{4}$ Department of Physics, I.I.T. (BHU), Varanasi-221005, India \\ ${ }^{3}$ Department of Physics and Astrophysics, University of Delhi, Delhi-110007, India \\ *Email: sadiqphy@gmail.com
}

In this present study the solid polymer Nanocomposite electrolytes (SPNEs) film were prepared by standard solution cast technique. These polymeric electrolytes films were characterization by FTIR and XRD analysis. Fourier transform Infrared (FTIR) spectroscopy has been used the analysis of interaction among the material present in microscopic level. FTIR spectrum of all the polymer nanocomposites films was recorded in the frequency range of $600-4000 \mathrm{~cm}^{-1}$ at resolution of $0.4 \mathrm{~cm}^{-1}$ by using a Bruker Tensor 27 Spectroscopy. The FTIR spectra were recorded in the absorbance mode. X-ray diffraction analysis is to obtain the evidence for confirmation of sample.

\section{Result of Ion-Ion and Polymer-Ion-Clay Interaction:}

Basically the ion-ion interactions are of two classes such as "ion dissociation effect" and "ion dissociation/pairing effect". The previous assist in the creation of mobile charge carriers i.e., free cations/anions.

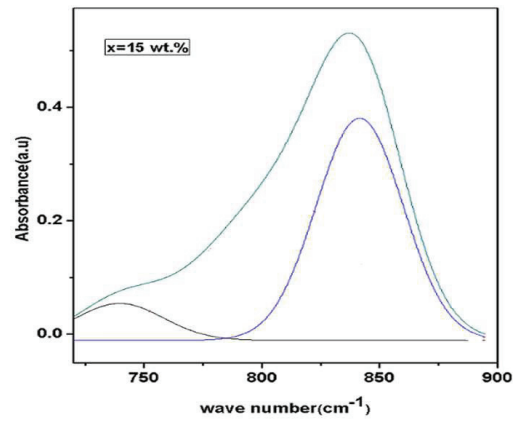

Figure 1: The deconvolution pattern of ion-ion and ion-clay interaction in $\mathrm{v}\left(\mathrm{PF}_{6}^{-}\right)$salt of (PAN-PEO $)_{6}$ $\mathrm{LiPF}_{6}+$ xwt. \% DMMT clay Nanocomposite.

However the from earlier report this ion interaction of having weak permittivity ( 4-6), swollen into a volatile polar organic solvent [1-
4]. As result of this expected to cause dissociation of cations $\left(\mathrm{Li}^{+}\right)$and anions $\left(\mathrm{PF}_{6}{ }^{-}\right)$ of the salt $\left(\mathrm{LiPF}_{6}\right)$ in the host polymer. So the chances of ions to remain both as the free charges (cation/anion) and ion pairs are highly probable and the free cation gets coordinated to the electron-rich site of the polymer backbone, whereas anion may remain hanged into the bulky polymer chains.

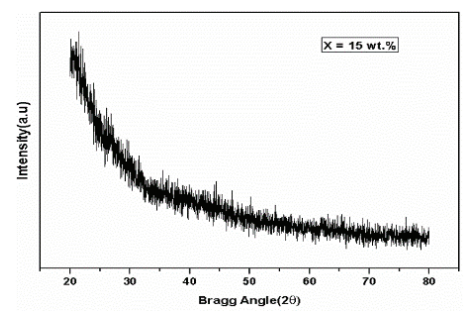

Figure 2: XRD pattern of (PAN-PEO) $\mathrm{LiPF}_{6}+\mathrm{xwt}$. $\%$ DMMT clay Nanocomposite.

The x-diffraction analysis (XRD) pattern of SPNEs with concentration of $x=15$ wt. $\%$ show the formation of Nanocomposite, where PS complex have been intercalated between the nanometric gallery of MMT.

Acknowledgements: Authors would like appreciate support of research facility of Central University of Punjab and partial financial support from UGC Start Up Grant [GP 25].

\section{References}

1. Shukla, N., \& Thakur, A. K., Journal of NonCrystalline Solids. 357 (22) (2011), 3689-3701.

2. Shukla, N., \& Thakur, A. K., Ionics. 15(3) (2009) 357-367. Sharma, A. L., \& Thakur, A. K., Ionics. 17(2) (2011), 135-143.

3. Sharma, A. L., \& Thakur, A. K., Ionics. 19(5) (2013), 795-809.

4. Sadiq, M., Sharma, A. L., \& Arya, A. (2016). Integrated Research Advances, 3(1), 16-20. 